\title{
THE BOUNDEDNESS OF A CLASS OF SEMICLASSICAL FOURIER INTEGRAL OPERATORS ON BESOV SPACES
}

\author{
REKIA MESSIOUENE and ABDERRAHMANE SENOUSSAOUI
}

\begin{abstract}
The aim of this paper is to discuss the Besov spaces bounds for semiclassical Fourier integral operator. We give the conditions that the symbol and the phase function must satisfy for this operator to be bounded.
\end{abstract}

MSC 2010. 35S30, 35S05, 47G30.

Key words. Semiclassical analysis, Fourier integral operator, symbol, phase, Besov spaces.

\section{REFERENCES}

[1] R.M. Beals, $L^{p}$ boundedness of Fourier integral operators, Mem. Amer. Math. Soc., 38 (264) (1982), 57p.+viii.

[2] P. Benner, $L_{p-} L_{p^{\prime}}$ estimates for Fourier integral operators related to hyperbolic equations, Math. Z., 152 (1977), 273-286.

[3] J. Bergh and J. Löfstörm, Interpolation Spaces. An Introduction, Vol. 223, Springer Verlag, Berlin, 1976.

[4] G. Boudraud, $L^{p}$ estimates for certain non regular pseudodifferential operators, Comm. Partial Differential Equations, 7 (1982), 1023-1033.

[5] J. J. Duistermaat, Fourier integral operators, Courant Institute Lecture Notes, New York, 1974

[6] O. Elong and A. Senoussaoui, On the $L^{p}$ boundedness of a class of semiclassical Fourier operators, Mat. Vesnik, 70 (2018), 189-203.

[7] C. Fefferman and E.M. Stein, $H^{p}$ spaces ef several variables, Acta Math., 129 (1972), $137-193$

[8] C. Harrat and A. Senoussaoui, On a class of h-Fourier integral operators, Demonstr. Math., 47 (2014), 595-606.

[9] L. Hörmander, Fourier integral operators. I, Acta Math. 127 (1971), 79-183.

[10] L. Hörmander, The analysis of linear partial differential operators III: Pseudo-differential operators, Springer Verlag, Berlin, 2007.

[11] A. Martinez, An Introduction to Semiclassical and Microlocal Analysis, Springer Verlag, 2002 .

[12] B. Messirdi and A. Senoussaoui, Parametrix du problème de Cauchy $C^{\infty}$ hyperbolique muni d'un système ordres de Leray-Volevîc, Z. Anal. Anwend., 24 (2005), 581-592.

[13] M. Moussai, Continuity of pseudodifferential operators on Bessel and Besov spaces, Serdica Math. J., 27 (2001), 249-262.

The authors would like to thank the referee for the careful reading and for relevant remarks, suggestions which helped them to improve the paper.

DOI: $10.24193 /$ mathcluj.2019.2.06 
[14] M. Moussai, On the continuity of pseudodifferential operators on Besov spaces, Analysis (Berlin), 26 (2006), 491-506.

[15] J. Peral, $L^{p}$ Estimate for the Wave Equation, Doctoral Dissertation, Princeton Univ., 1987.

[16] Q. Qingjiu, The Besov space boundedness for certain Fourier integral operators, Acta Math. Sin., 5 (1985), 167-174.

[17] D. Robert, Autour de l'approximation semi classique, Birkäuser, 1987.

[18] E.M. Stein, Interpolation of linear operators, Trans. Amer. Math. Soc., 83 (1956), 482492.

[19] H. Triebel, Theory of Function Spaces, Birkhäuser, Basel, 1983.

Received April 9, 2018

Accepted January 31, 2019
Université Oran1, Ahmed Ben Bella Laboratoire de Mathématiques Fondamentales et Appliquées d'Oran (LMFAO)

B.P. 1524 El M'naouar, Oran, Algeria

E-mail: rekiamessiouene@yahoo.fr

E-mail: senoussaoui_abdou@yahoo.fr 